\title{
Twenty Years of the Food Cravings Questionnaires: a Comprehensive Review
}

\author{
Adrian Meule ${ }^{1,2}$ \\ Published online: 12 February 2020 \\ (C) The Author(s) 2020
}

\begin{abstract}
Purpose of Review The Food Cravings Questionnaires (FCQs; Cepeda-Benito, Gleaves, Williams, \& Erath, 2000) are among the most widely used instruments for measuring food cravings. In addition to the Food Cravings Questionnaire-Trait (FCQ-T) and the Food Cravings Questionnaire-State (FCQ-S), several modified versions have been developed as well. For their 20th anniversary, this article provides a comprehensive description of the FCQs and reviews studies on their psychometric properties and correlates.

Recent Findings The FCQs and their modified versions have excellent internal reliability. Expectedly, the FCQ-T (and its derivatives) has higher retest-reliability than the FCQ-S as the FCQ-S is sensitive to situational changes such as food deprivation and food intake. However, while the FCQ-T is largely unaffected by such momentary states, it is also sensitive to change during weight-loss treatments and other interventions. Factor structure of the FCQ-T and FCQ-S has only partially been replicated. Construct validity of the FCQs is supported by experimental and longitudinal studies that measured food craving and food consumption in the laboratory and with ecological momentary assessment.

Summary Numerous studies support reliability and validity of the FCQs and their modified versions, yet findings about their factor structures are inconsistent. Thus, using total scores or the short versions of the FCQs may be preferable.
\end{abstract}

Keywords Food $\cdot$ Craving $\cdot$ Hunger $\cdot$ Chocolate $\cdot$ Assessment $\cdot$ Psychometrics

\section{Introduction}

Food craving refers to an intense desire to consume a specific food [1]. This specificity differentiates it from general feelings of hunger, which can be alleviated by consumption of any type of food [2]. Craved foods usually have a high energy density due to their high carbohydrate and/or fat content. In North American and European countries, chocolate and chocolate-containing foods are the most commonly craved foods, particularly among women [3-8]. Food craving is a multidimensional experience as it includes cognitive (e.g., thinking about food), emotional (e.g., desire to eat or changes in mood), behavioral (e.g., seeking and consuming food), and

This article is part of the Topical Collection on Food Addiction

Adrian Meule

ameule@med.lmu.de

1 Department of Psychiatry and Psychotherapy, University Hospital, LMU Munich, Munich, Germany

2 Schoen Clinic Roseneck, Prien am Chiemsee, Germany physiological (e.g., salivation) aspects [9]. Moreover, while the experience of a food craving is a transient state, there are also more stable individual differences in the frequency and intensity of experiencing food cravings in general (which is sometimes labeled trait food craving [10]).

Twenty years ago, Cepeda-Benito and colleagues developed the Food Cravings Questionnaires (FCQs), which are two self-report instruments for the measurement of the multidimensional nature of food craving as a state and trait [11]. The FCQs would turn out to be among the most widely used measures for the assessment of food cravings. As of this writing, the article by Cepeda-Benito and colleagues has been cited more than 200 times according to Web of Science and more than 400 times according to Google Scholar (Fig. 1). The FCQs have also been translated into several other languages and different modified versions have been developed. Therefore, the current article provides a detailed description of the FCQs and their modified versions, reviews their psychometric properties and correlates, and evaluates the scales in light of other self-report measures for the assessment of food craving. 
Fig. 1 Citation numbers of different self-report measures for the assessment of food cravings (as of June 2019). Only food craving measures with at least 50 citations (according to Google Scholar) were included

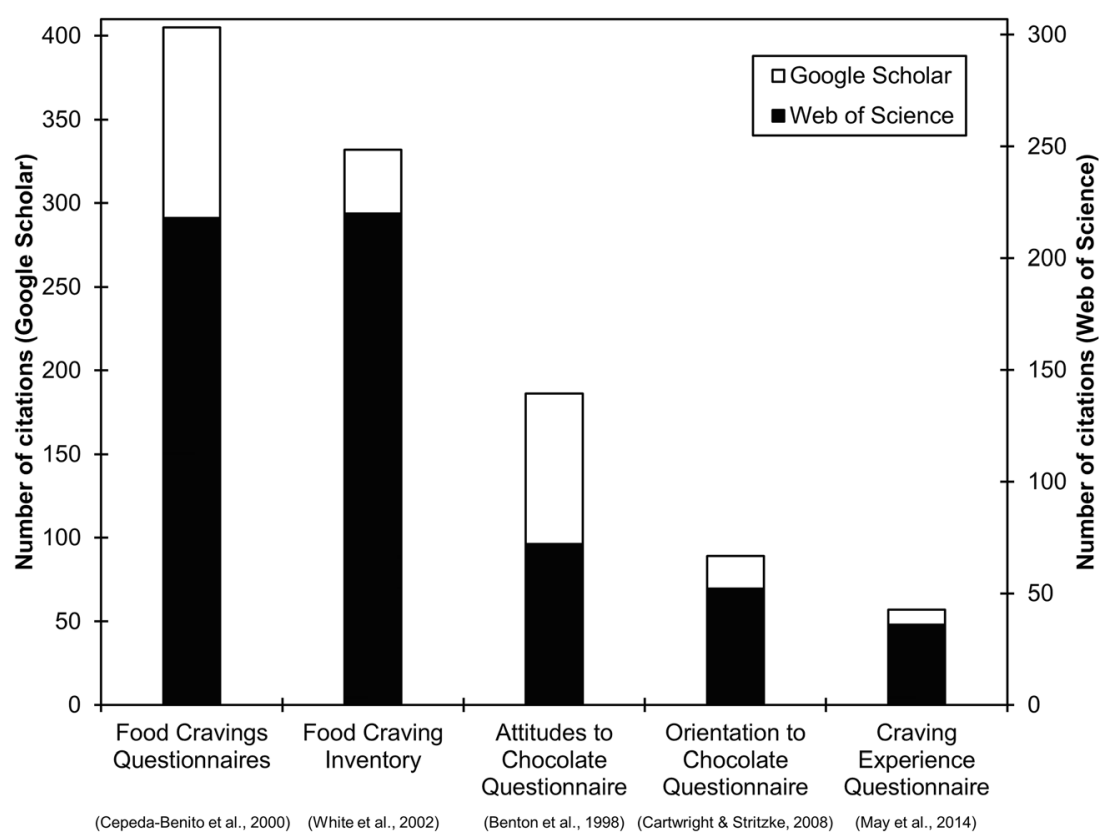

\section{Food Cravings Questionnaire-Trait}

\section{Description}

The Food Cravings Questionnaire-Trait (FCQ-T) measures the frequency and intensity of food craving experiences in general. The questionnaire has 39 items and response categories range from $1=$ never to $6=$ always (Table 1 ). There are no inverted items. Responses to all items are summed up for a total score. Thus, higher scores represent more frequent and intense food cravings. Several subscale scores can be also calculated. The FCQ-T has been translated into at least seven other languages: Spanish [12], German [13], Italian [14], Portuguese [15, 16], Persian [17], Turkish [18], and Chinese [19].

\section{Factor Structure}

Cepeda-Benito and colleagues [11] found a nine-factor structure of the FCQ-T in two samples of undergraduate students:

- Having intentions and plans to consume food (Items 5, 18, 23)

- Anticipation of positive reinforcement that may result from eating (Items 9, 10, 15, 24, 38)

- Anticipation of relief from negative states and feelings as a result of eating (Items 16, 19, 21)

- Lack of control over eating (Items 2, 3, 22, 25, 26, 29)

- Thoughts and preoccupation with food (Items 6, 8, 27, 28, $31,32,33$ )

- Craving as a physiological state (Items $11,12,13,14$ )
- Emotions that may be experienced before or during food cravings or eating (Items 20, 30, 34, 39)

- Cues that may trigger food cravings (Items 1, 35, 36, 37)

- Guilt from cravings and/or for giving into them (Items 4, $7,17)$

This factor structure was replicated in some studies, for example for the Spanish version (including a study in women with anorexia and bulimia nervosa $[12,20,21])$, the Italian version [14], and the Turkish version [18]. Moreover, full measurement invariance was found across American and Spanish participants [12]. Using a Portuguese version, one study could replicate the nine factors [16] whereas model fit was poor in another study [22]. Several studies could not replicate the nine-factor structure and instead suggested fewer factors. For example, an eight-factor structure was found in a sample of persons with overweight [23], a seven-factor structure was found in a sample of obese bariatric surgery candidates [24, 25], a six-factor structure was found for the German version [13] and Chinese version [19], a five-factor structure was found for the Persian version [17], and a four-factor structure was found for the Spanish version in a sample from Cuba [26]. Thus, while there is some support for the nine subscales of the FCQ-T, factorial validity may be limited in other cultures or languages and in specific populations (e.g., overweight persons).

\section{Reliability}

Internal reliability of the total scale is excellent $(\alpha>.90)$ but lower for the subscales [11-14, 16-21]. Similarly, retestreliability over few weeks was good for the FCQ-T total score 
Table 1 Items of the Food Cravings Questionnaire-Trait

Items

Response categories

$\begin{aligned} & \text { Never/not Rarely Sometimes Often Usually Always } \\ & \text { applicable }\end{aligned}$
.

1. Being with someone who is eating often makes me hungry.

\begin{tabular}{|c|c|c|c|c|c|}
\hline 1 & 2 & 3 & 4 & 5 & 6 \\
\hline 1 & 2 & 3 & 4 & 5 & 6 \\
\hline 1 & 2 & 3 & 4 & 5 & 6 \\
\hline 1 & 2 & 3 & 4 & 5 & 6 \\
\hline 1 & 2 & 3 & 4 & 5 & 6 \\
\hline 1 & 2 & 3 & 4 & 5 & 6 \\
\hline 1 & 2 & 3 & 4 & 5 & 6 \\
\hline 1 & 2 & 3 & 4 & 5 & 6 \\
\hline 1 & 2 & 3 & 4 & 5 & 6 \\
\hline 1 & 2 & 3 & 4 & 5 & 6 \\
\hline 1 & 2 & 3 & 4 & 5 & 6 \\
\hline 1 & 2 & 3 & 4 & 5 & 6 \\
\hline 1 & 2 & 3 & 4 & 5 & 6 \\
\hline 1 & 2 & 3 & 4 & 5 & 6 \\
\hline 1 & 2 & 3 & 4 & 5 & 6 \\
\hline 1 & 2 & 3 & 4 & 5 & 6 \\
\hline 1 & 2 & 3 & 4 & 5 & 6 \\
\hline 1 & 2 & 3 & 4 & 5 & 6 \\
\hline 1 & 2 & 3 & 4 & 5 & 6 \\
\hline 1 & 2 & 3 & 4 & 5 & 6 \\
\hline 1 & 2 & 3 & 4 & 5 & 6 \\
\hline 1 & 2 & 3 & 4 & 5 & 6 \\
\hline 1 & 2 & 3 & 4 & 5 & 6 \\
\hline 1 & 2 & 3 & 4 & 5 & 6 \\
\hline 1 & 2 & 3 & 4 & 5 & 6 \\
\hline 1 & 2 & 3 & 4 & 5 & 6 \\
\hline 1 & 2 & 3 & 4 & 5 & 6 \\
\hline 1 & 2 & 3 & 4 & 5 & 6 \\
\hline 1 & 2 & 3 & 4 & 5 & 6 \\
\hline 1 & 2 & 3 & 4 & 5 & 6 \\
\hline 1 & 2 & 3 & 4 & 5 & 6 \\
\hline 1 & 2 & 3 & 4 & 5 & 6 \\
\hline 1 & 2 & 3 & 4 & 5 & 6 \\
\hline 1 & 2 & 3 & 4 & 5 & 6 \\
\hline 1 & 2 & 3 & 4 & 5 & 6 \\
\hline 1 & 2 & 3 & 4 & 5 & 6 \\
\hline 1 & 2 & 3 & 4 & 5 & 6 \\
\hline 1 & 2 & 3 & 4 & 5 & 6 \\
\hline 1 & 2 & 3 & 4 & 5 & 6 \\
\hline
\end{tabular}

2. When I crave something, I know I will not be able to stop eating once I start. ${ }^{a}$

3. If I eat what I am craving, I often lose control and eat too much. ${ }^{a}$

4. I hate it when I give in to cravings.

6. I feel like I have food on my mind all the time. ${ }^{2}$

7. I often feel guilty for craving certain foods.

8. I find myself preoccupied with food. ${ }^{\mathrm{a}, \mathrm{b}}$

9. I eat to feel better.

10. Sometimes, eating makes things seem just perfect.

11. Thinking about my favorite foods makes my mouth water.

12. I crave foods when my stomach is empty.

13. I feel as if my body asks me for certain foods.

14. I get so hungry that my stomach seems like a bottomless pit.

15. Eating what I crave makes me feel better.

16. When I satisfy a craving I feel less depressed.

17. When I eat what I am craving I feel guilty about myself.

18. Whenever I have cravings, I find myself making plans to eat. ${ }^{a}$

19. Eating calms me down.

20. I crave foods when I feel bored, angry, or sad. ${ }^{\mathrm{a}}$

21. I feel less anxious after I eat.

22. If I get what I am craving I cannot stop myself from eating it.

23. When I crave certain foods, 1 usually try to eat them as soon as I can.

24. When I eat what I crave I feel great.

25. I have no will power to resist my food crave. ${ }^{a, b}$

26. Once I start eating, I have trouble stopping. ${ }^{\text {a }}$

27. I cannot stop thinking about eating no matter how hard I try. ${ }^{\mathrm{a}, \mathrm{b}}$

28. I spend a lot of time thinking about whatever it is I will eat next.

29. If I give in to a food craving, all control is lost. ${ }^{\mathrm{a}}$

30. When I'm stressed out, I crave food. ${ }^{\text {b }}$

31. I daydream about food.

32. Whenever I have a food craving, I keep on thinking about eating until I actually eat the food. ${ }^{\mathrm{a}, \mathrm{b}}$

33. If I am craving something, thoughts of eating it consume me. a,b $^{\text {a }}$

34. My emotions often make me want to eat. ${ }^{\text {a }}$

35. Whenever I go to a buffet I end up eating more than what I needed.

36. It is hard for me to resist the temptation to eat appetizing foods that are in my reach., ${ }^{\mathrm{a}, \mathrm{b}}$

37. When I am with someone who is overeating, I usually overeat too.

38. When I eat food, I feel comforted.

39. I crave foods when I'm upset.

Participants are instructed to indicate how frequently each statement is true for them in general

${ }^{\text {a }}$ Items included in the Food Cravings Questionnaire-Trait-reduced [58]

${ }^{\mathrm{b}}$ Items included in the abbreviated Food Cravings Questionnaire-Trait by Maranhão et al. [22] 
$(r>.80)$ but lower for the subscale scores in several studies $[11,13,17,19,23]$. Thus, the FCQ-T is an internally reliable measure and scores are temporally stable. Yet, the scale is also sensitive to change during interventions, for example, in the course of obesity or eating disorder treatment. For instance, decreases in FCQ-T scores have been reported in cognitivebehavioral weight-loss interventions [27, 28], a food cravingrelated self-help intervention [29], heart rate variability biofeedback training [30], neurofeedback training [31], approach bias modification training [32], and after bariatric surgery [33].

\section{Validity}

A plethora of studies have examined correlates of the FCQ-T, which are too numerous to be reviewed in detail here. Therefore, the description of studies in support of validity of the FCQ-T focuses on the strongest evidence from experimental and longitudinal studies. Yet, some correlates based on descriptive, cross-sectional studies are briefly described. First, sex differences have been consistently found with women having higher FCQ-T scores than men (e.g., [34]). Second, FCQ-T scores are associated with eating disorders and obesity. Specifically, individuals with bulimia nervosa and binge eating disorder have higher FCQ-T scores than individuals without eating disorders, and individuals with obesity have higher FCQ-T scores than individuals with normal weight [35-38]. Of note, however, is that the association between the FCQ-T and (binge-related) eating disorders is much stronger than the association with obesity and, similarly, the positive correlation between FCQ-T scores and body mass index is usually small (e.g., [13, 39]). Third, scores on the FCQ-T are weakly associated with many psychological variables (e.g., personality traits $[40,41]$ ) and strongly associated with other constructs that can be summarized under the umbrella term "uncontrolled eating" such as binge eating, disinhibited eating, emotional eating, hedonic hunger, or food addiction $[42,43]$.

Construct validity of the FCQ-T is supported by studies that examined food cue reactivity (i.e., behavioral, cognitiveaffective, or neural responses to food cues). For example, trait food cravers as identified with the FCQ-T showed a stronger approach tendency towards high-calorie food in a reaction time task than those with low FCQ-T scores [44] and stronger increases in state craving (as measured with the FCQ-S) during performance of a working memory task that included pictures of palatable foods [45]. Scores on the FCQ-T were also weakly correlated with higher craving intensity when participants had to imagine eating their favorite food [46]. Higher FCQ-T scores related to stronger reward-related brain activations [47] and behavioral disinhibition [48] in response to high-calorie versus low-calorie food stimuli. They also weakly correlated with a composite genetic index reflecting the influence of multiple functional polymorphic dopamine markers, which have been associated with striatal dopamine signaling [49].

Predictive validity of the FCQ-T is supported by studies that examined food intake and changes in body weight. In a sample of children and adolescents, for example, higher FCQ$\mathrm{T}$ scores related to higher liking ratings for high-calorie foods and a stronger tendency to select these foods for consumption in a bogus taste test [50]. In a prospective study, higher FCQ$\mathrm{T}$ scores predicted lower weight loss after bariatric surgery [51]. Support for discriminant validity can be seen in thatas opposed to the FCQ-S - the FCQ-T is largely unaffected by momentary states such as hunger and satiety. For example, FCQ-T scores did not correlate with length of food deprivation (i.e., the time since the last meal) and did not differ substantially before and after eating breakfast $[12,20]$.

\section{Food Cravings Questionnaire-State}

\section{Description}

The Food Cravings Questionnaire-State (FCQ-S) measures the intensity of momentary food craving. The questionnaire has 15 items and response categories range from $1=$ strongly disagree to $5=$ strongly agree (Table 2 ). There are no inverted items. Responses to all items are summed up for a total score. Thus, higher scores represent more intense current food craving. Several subscale scores can be also calculated. The FCQ$\mathrm{S}$ has been translated into at least five other languages: Spanish [12], German [13], Italian [52], Portuguese [15, 16], and Korean [53].

\section{Factor Structure}

Cepeda-Benito and colleagues [11] found a five-factor structure of the FCQ-S in two samples of undergraduate students:

- An intense desire to eat (Items 1,2,3)

- Anticipation of positive reinforcement that may result from eating (Items 4, 5, 6)

- Anticipation of relief from negative states and feelings as a result of eating (Items 7, 8, 9)

- Lack of control over eating (Items 10, 11, 12)

- Craving as a physiological state (i.e., hunger) (Items 13, $14,15)$

The five factors were replicated in some studies $[12,16$, 52], including one study in women with anorexia and bulimia nervosa [21]. In contrast to the FCQ-T, however, only partial measurement invariance was found across American and Spanish participants. Moreover, model fit of the five-factor model was poor in a study using a Portuguese version of the FCQ-S [22] and two studies suggested fewer than five factors 
Table 2 Items of the Food Cravings Questionnaire-State

\begin{tabular}{|c|c|c|c|c|c|}
\hline \multirow[t]{2}{*}{ Items } & \multicolumn{5}{|c|}{ Response categories } \\
\hline & $\begin{array}{l}\text { Strongly } \\
\text { disagree }\end{array}$ & Disagree & Neutral & Agree & $\begin{array}{l}\text { Strongly } \\
\text { agree }\end{array}$ \\
\hline $\begin{array}{l}\text { 1. I have an intense desire to eat [one or more specific } \\
\text { foods]. }\end{array}$ & 1 & 2 & 3 & 4 & 5 \\
\hline 2. I'm craving [one or more specific foods]. ${ }^{\mathrm{a}}$ & 1 & 2 & 3 & 4 & 5 \\
\hline 3. I have an urge for [one or more specific foods]. ${ }^{\mathrm{a}}$ & 1 & 2 & 3 & 4 & 5 \\
\hline $\begin{array}{l}\text { 4. Eating [one or more specific foods] would make } \\
\text { things seem just perfect. }\end{array}$ & 1 & 2 & 3 & 4 & 5 \\
\hline $\begin{array}{l}\text { 5. If I were to eat what I am craving, I am sure my } \\
\text { mood would improve. }\end{array}$ & 1 & 2 & 3 & 4 & 5 \\
\hline $\begin{array}{l}\text { 6. Eating [one or more specific foods] would feel } \\
\text { wonderful. }\end{array}$ & 1 & 2 & 3 & 4 & 5 \\
\hline $\begin{array}{l}\text { 7. If I ate something, I would not feel so sluggish and } \\
\text { lethargic. }\end{array}$ & 1 & 2 & 3 & 4 & 5 \\
\hline $\begin{array}{l}\text { 8. Satisfying my craving would make me feel less } \\
\text { grouchy and irritable. }\end{array}$ & 1 & 2 & 3 & 4 & 5 \\
\hline $\begin{array}{l}\text { 9. I would feel more alert if I could satisfy my } \\
\text { craving. }\end{array}$ & 1 & 2 & 3 & 4 & 5 \\
\hline $\begin{array}{l}\text { 10. If I had [one or more specific foods], I could not } \\
\text { stop eating it. }\end{array}$ & 1 & 2 & 3 & 4 & 5 \\
\hline $\begin{array}{l}\text { 11. My desire to eat [one or more specific foods] } \\
\text { seems overpowering. }{ }^{\text {a }}\end{array}$ & 1 & 2 & 3 & 4 & 5 \\
\hline $\begin{array}{l}\text { 12. I know I'm going to keep on thinking about [one } \\
\text { or more specific foods] until I actually have it. }\end{array}$ & 1 & 2 & 3 & 4 & 5 \\
\hline 13. I am hungry. & 1 & 2 & 3 & 4 & 5 \\
\hline $\begin{array}{l}\text { 14. If I ate right now, my stomach would not feel as } \\
\text { empty. }\end{array}$ & 1 & 2 & 3 & 4 & 5 \\
\hline 15. I feel weak because of not eating. & 1 & 2 & 3 & 4 & 5 \\
\hline
\end{tabular}

Participants are instructed to indicate the extent to which they agree with each statement right now, at this very moment

${ }^{a}$ Items included in the abbreviated Food Cravings Questionnaire-State by Maranhão et al. [22]

(four factors [23] and three factors [13]). Thus - similar to the FCQ-T - support for factorial validity of the FCQ-S is limited as factor structure could only be replicated partially.

\section{Reliability}

As for the FCQ-T, the FCQ-S has excellent internal reliability $(\alpha>.90,[11-13,54])$. Retest-reliability is low (usually $r$ $<.60,[11,55])$. Yet, what would be considered insufficient values for a trait-related measure is indeed to be expected for the FCQ-S as a state-dependent measure. However, an interesting future avenue would be to examine retest-reliability of the FCQ-S under controlled conditions, for example, after a standardized fasting period or a standardized meal. If such conditions are kept constant across measurement points, it may well be that retest-reliability for the FCQ-S is high. More importantly, however, is that the FCQ-S is sensitive to change during various manipulations: scores increase during food cue exposure (e.g., food pictures) or exposure to real food [52, 54, 56-61] and decrease after exercise [62], methylphenidate ingestion [63], repetitive transcranial magnetic stimulation [64, 65], infraslow neurofeedback training [66], and food intake $[11,23,59]$.

\section{Validity}

Construct validity of the FCQ-S is supported by studies that examined associations with momentary states such as current food deprivation and affect. It has consistently be found that a longer food deprivation (i.e., the time since the last meal) relates to higher FCQ-S scores [12, 13, 20, 55, 58], and, in one study, higher current negative affect was moderately correlated with the FCQ-S as well [13]. In a sample of persons with Type 2 diabetes mellitus, higher FCQ-S scores (adapted to refer to carbohydrate-rich foods) related to higher $\mathrm{HbA}_{1 \mathrm{c}}$ levels (indicating long-term blood sugar levels). Moreover, they changed as a function glycaemic control: carbohydraterelated FCQ-S scores decreased in those with lower $\mathrm{HbA}_{1 \mathrm{c}}$ levels (indicating improved glycaemic control) and increased in those with higher $\mathrm{HbA}_{1 \mathrm{c}}$ levels at follow-up measurement.

Predictive validity of the FCQ-S has been supported by studies that examined hedonic responses to food cues and food consumption. For example, higher FCQ-S scores related 
to more positive evaluations of high-caloric food in implicit measures such as the Affect Misattribution Procedure [67] and impulsive reactions to pictorial food stimuli [68]. Moreover, higher FCQ-S scores related to higher subsequent food intake in the laboratory [54]. Support for discriminant validity can be seen in that - as opposed to the FCQ-T-the FCQ-S shows weak or no relationships with trait-like eating behaviors (e.g., restrained or disinhibited eating as measured with the ThreeFactor Eating Questionnaire [11]) and body mass index [13].

\section{Modified Versions}

\section{General Food Cravings Questionnaires}

The General FCQs are modified versions of the FCQs developed by Nijs and colleagues [69]. The modifications include translating the scale into Dutch, substituting the word craving with an appropriate Dutch description, and references to one or more specific foods included in the items of the FCQ-S were rephrased in more general terms (e.g., something tasty). For the General FCQ-T (G-FCQ-T), principal component analysis suggested a four-factor structure. Further inspection lead the authors to exclude 17 items, which either had low factor loadings on any of the four factors or loaded equally high on various factors. One additional item was removed because its content did not correspond with the factor on which it loaded. Thus, the G-FCQ-T consists of 21 items. The General FCQ-S (G-FCQ-S) consists of 15 items with a five-factor structure, similar to the FCQ-S.

Psychometric properties of both the G-FCQ-T and GFCQ-S are largely similar to the original FCQs. These include, for example, excellent internal reliabilities, adequate retest-reliability of the G-FCQ-T across three weeks, moderate-to-high correlations between the G-FCQ-T and other eating behavior traits, and no or small correlations between the G-FCQ-S and these eating behavior traits. Sensitivity to change of G-FCQ-S scores is indicated by decreased scores after food intake $[69,70]$ and increased scores after sleep deprivation [71]. Similar to the FCQ-T, the GFCQ-T is also sensitive to change as demonstrated, for example, in decreased scores after bariatric surgery, energyrestricted diets, and mindful eating interventions [72-75].

Although the General FCQs were originally developed in Dutch, the English items are displayed in the article by Nijs et al. [69]. Accordingly, these English versions have also been used in several studies (e.g., [71, 72]). Moreover, the G-FCQ$\mathrm{T}$ has been translated into Korean [76, 77]. Yet, it is unclear what the actual differences to the original FCQs are. When examining the English items of the G-FCQ-T (cf. Table 1 in the article by Nijs et al. [69]), it appears that these are equivalent to the items of the FCQ-T (Table 1). Thus, it seems that - at least when the scale is used in English and not in Dutch - the G-FCQ-T should rather be considered a 21- item short form of the FCQ-T instead of representing a conceptually different questionnaire. For the G-FCQ-S, it seems that the only difference to the items of the FCQ-S (Table 2) is that items refer to tasty foods instead of one or more specific foods. Therefore, as craved foods are usually high-caloric and palatable [3], it appears that the conceptual differences between the G-FCQ-S and FCQ-S are minimal.

\section{Food Cravings Questionnaire-Trait-Reduced}

As outlined above, the FCQ-T has very high internal reliability and factor structure could only be replicated inconsistently. Moreover, many researchers only analyze (or report) FCQ-T total scores, which might be due to the fact that correlates of the FCQ-T are largely similar across the nine subscales. This motivated the development of a short version of the FCQ-T: the FCQ-T-reduced (FCQ-T-r, [58]). For the FCQ-T-r, 15 of the 39 items of the German FCQ-T that had the highest item-total-correlations were chosen (Table 1). Although the FCQ-T- $r$ was originally developed in German [58], it has since been used and evaluated in English [78], Portuguese [79], French [80], Persian [81], Spanish [26], and Italian [82, 83 ] as well. A sum score of 50 discriminated between individuals with and without "food addiction" (as measured with the Yale Food Addiction Scale 2.0) with high sensitivity and specificity and has, thus, been proposed as a possible cut-off score that may indicate pathologically elevated, clinically relevant levels of trait food craving [84]. The FCQ-T-r has been recommended as a measure in studies on weight loss and weight maintenance by the Accumulating Data to Optimally Predict Obesity Treatment (ADOPT) Core Measures Project, which selected measures that are reliable, valid, brief, publicly available, and easily administered and scored [85].

The FCQ-T- $r$ has a unidimensional structure [58], which was replicated in several studies $[26,78-80,82,83]$. The FCQ-T-r has excellent internal reliability $(\alpha>.90,[26,55$, 78-83]). Retest-reliability over two weeks was excellent for the Persian version $(r=.92$, [81]) and - considering the long time period of six months - was also good for the German version $(r=.74,[55])$. The FCQ-T- $\mathrm{r}$ is also sensitive to change as demonstrated, for example, in decreases of scores during a neurofeedback intervention [86] and during mindful eating interventions $[87,88]$.

Similar to the FCQ-T, construct validity is supported by studies that examined food cue reactivity in the laboratory. For example, higher FCQ-T-r scores predicted stronger increases in state food craving during performance of a working memory task that included pictures of palatable foods [58]. Predictive validity is supported by prospective studies. In female university freshmen, for example, higher FCQ-T-r scores at the beginning of the first semester predicted increases in disinhibited eating as well as decreases in perceived self-regulatory success in weight regulation at the end of the semester [89]. Scores on the FCQ-T- 
$\mathrm{r}$ predicted thoughts about high-calorie snack foods in daily life as measured with ecological momentary assessment. Moreover, FCQ-T-r scores moderated the relationship between craving for and consumption of these foods in that experiencing a craving more likely translated into consumption of snack foods in individuals with high FCQ-T-r scores than in those with low scores [3]. Scores on the FCQ-T- $r$ also predicted a higher intentionbehavior gap in daily life as measured with ecological momentary assessment: those with higher FCQ-T-r scores were less likely to actually restrict their eating behavior on a given day when they intended to do so on the previous day [90]. Finallysimilar to the FCQ-T - discriminant validity is supported in that scores on the FCQ-T-r were unrelated to length of food deprivation (i.e., the time since the last meal $[55,58])$.

\section{Chocolate-Specific Versions}

Chocolate version of the Food Cravings Questionnaire-Trait Rodríguez and colleagues [91] adapted both the English and Spanish FCQ-T for the assessment of chocolate cravings. For this, items were reformulated such that references to food were replaced with references to chocolate. The nine-factor structure and excellent internal reliability of the original FCQ-T was replicated, yet measurement was only partially invariant across British and Spanish women [91]. Validity of the scale was supported in that high trait chocolate cravers as identified with the chocolate-adapted FCQ-T ate more chocolate in a laboratory taste test than low trait chocolate cravers [92].

\section{Chocolate version of the Food Cravings Questionnaire-Trait-} reduced For the chocolate version of the FCQ-T-r, the term chocolate was incorporated into each item of the German FCQ-T-r, but the English items are also displayed in the article by Meule and Hormes [93]. In contrast to the FCQ$\mathrm{T}-\mathrm{r}$, exploratory factor analysis suggested two factors: one related primarily to thoughts about chocolate and one related primarily to lack of control over chocolate consumption. Internal reliability was excellent for the total scale and the subscales [93]. There are no data on retest-reliability yet, but - similar to the FCQ-T- - - the chocolate-adapted version is sensitive to change as indicated by decreased scores over a ten-day period during which participants had to record their daily chocolate consumption at the end of each day [94].

Construct validity is supported by studies that examined chocolate cue reactivity. For example, trait chocolate cravers as identified with the chocolate-adapted FCQ-T-r rated chocolate pictures as more pleasant, thought more about chocolate following presentation of a pictorial chocolate cue, and showed higher activation in the striatum during this period than those with low chocolate-related FCQ-T-r scores [95]. Similar to the FCQ-T, higher scores on the chocolate-adapted
FCQ-T-r related to stronger approach tendencies towards chocolate stimuli in a reaction time task [96].

Predictive validity is supported by studies that examined chocolate intake. Higher chocolate-related FCQ-T-r scores predicted higher chocolate consumption in the laboratory in participants who showed increases in salivary flow during a chocolate exposure [93]. Furthermore, scores on the chocolate-adapted FCQ-T-r predicted chocolate craving intensity and frequency as well as chocolate consumption quantity and frequency in daily life as measured with ecological momentary assessment [94]. Similar to the FCQ-T and FCQ$\mathrm{T}-\mathrm{r}$, discriminant validity is supported by the absent relationship of scores with current food deprivation (i.e., the time since the last meal [93]).

Chocolate version of the Food Cravings Questionnaire-State. For the chocolate version of the FCQ-S, references to one or more specific foods in items 1-12 of the German FCQ-S were substituted with chocolate. The three items (13-15) for the measurement of hunger, which do not allow for a reference to specific foods (Table 2), were not changed. Although the scale was developed in German, the English items are also displayed in the article by Meule \& Hormes [93]. In contrast to the original FCQ-S, a clear two-factor structure was found for the chocolate-adapted version representing a chocolate craving factor (Items 1-12) and a hunger factor (Items 1315). Internal reliabilities were good for the two subscales and the total scale [93]. Similar to the FCQ-S, scores are sensitive to change as they increased during chocolate exposure [93]. Furthermore, scores on the chocolate-adapted FCQ-S increased during a two-week chocolate deprivation in trait chocolate cravers [97] and during approach-avoidance reaction time tasks with pictorial chocolate stimuli on touchscreen devices $[94,96]$.

Construct validity has been supported in that higher scores on the hunger subscale - but not on the chocolate craving subscale - correlated with longer food deprivation (i.e., the time since the last meal). Moreover, increases in current chocolate craving - but not increases in current hungercorrelated with increases in salivary flow during a chocolate exposure [93]. Predictive validity has been supported by studies that examined hedonic responses to chocolate cues and chocolate consumption. For example, higher scores on the chocolate-adapted FCQ-S related to more positive evaluations of chocolate-containing foods in implicit measures such as the Affect Misattribution Procedure and the Implicit Association Test [97]. When examining interactive effects between the chocolate craving and the hunger subscale, it was found that higher chocolate craving related to more positive evaluations of chocolate only in hungry participants [98]. Moreover, higher scores on the chocolate craving subscale-but not on the hunger 
subscale-predicted higher chocolate consumption in the laboratory [93]. Similar to the FCQ-S, discriminant validity has been supported by absent relationships with body mass index [93].

\section{Short Versions of the Portuguese Food Cravings Questionnaires}

Recently, Maranhão and colleagues suggested abbreviated forms of a Portuguese version of the FCQs [22]. The short form of the FCQ-T consists of eight items, which stem from the original FCQ-T's subscales thoughts or preoccupation with food (4 items), having intentions and plans to consume food (1 item), emotions that may be experienced before or during food cravings or eating ( 1 item), cues that may trigger food cravings ( 1 item), and lack of control over eating ( 1 item; Table 1). The short form of the FCQ-S consists of five items, which stem from the original FCQ-S's subscales intense desire to eat (3 items) and lack of control over eating ( 2 items; Table 2). Both the abbreviated FCQ-T and the abbreviated FCQ-S had a unidimensional structure.

\section{Recommendations}

\section{Different Versions of the FCQs}

For the assessment of trait food craving, there are six versions, which differ in item content and number of items. The original FCQ-T has 39 items and does not specify certain foods that participants should think of when completing the scale [11]. There are three short versions of this questionnaire that have either 21 items (G-FCQ-T, [69]), 15 items (FCQ-T-r, [58]), or 8 items (abbreviated FCQ-T, [22]). For the original 39-item FCQ-T and for the 15-item FCQ-T-r, there are chocolateadapted versions that include the very same items except that they specifically refer to chocolate $[91,93]$. Thus, researchers have to decide whether they want to measure food craving in general or chocolate craving in particular and whether they need to do this more comprehensively by using the longer versions or more efficiently by using the shorter versions. Using the shorter versions may come at the expense of losing information as they assess fewer aspects of food craving than the full versions. For example, both the FCQ-T-r and the abbreviated FCQ-T do not include any items of the original FCQ-T's subscales anticipation of positive reinforcement that may result from eating, anticipation of relief from negative states and feelings as a result of eating, craving as a physiological state, and guilt from cravings and/or for giving into them. However, given the limited factorial validity of the FCQ-T, shorter versions may be preferred over the full versions, particularly when there is no need to analyze the subscales of the FCQ-T separately.
For the assessment of state food craving, there are three different versions of the FCQ-S with 15 items and one version with five items. The original FCQ-S measures state craving for one or more particular foods, yet these are not specified (i.e., each participant can think of different foods when completing the scale [11]). The G-FCQ-S measures state craving for tasty foods (i.e., the type of foods are broadly defined, but each participant can still think of different foods within the category of tasty foods [69]). The chocolate-adapted version of the FCQ-S measures state craving for chocolate-containing foods [93]. In addition, each of these three questionnaires include a hunger subscale, items of which do not refer to specific foods. The abbreviated FCQ-S only has five items, which do not include any items from the hunger subscale [22]. Thus, researchers need to decide for which type of foods they want to measure current food craving (unspecified, tasty foods, chocolate) and, in the case of the FCQ-S, whether they want to use the original 15 -item version or the 5 -item short form. The abbreviated FCQ-S may be preferred over the original version in certain cases (e.g., when the questionnaire is completed several times in a laboratory experiment). Yet, the original version may be preferable in studies in which assessment of current hunger provides essential information, as these items are not included in the short version.

\section{Trait Vs. State Food Craving}

In the previous sections, it has been demonstrated that the FCQ-T and FCQ-S both show discriminant validity, that is, that trait and state food craving are distinguishable concepts. While the FCQ-S is affected by momentary states and manipulations such as current food deprivation, food cue exposure, and food intake, the FCQ$\mathrm{T}$ is largely unaffected by such factors and scores are more stable over time. However, this does not mean that the FCQ-T and FCQ-S are independent from each other - they are indeed positively (yet weakly) correlated [55]. It may be that individuals with high FCQ-T scores (i.e., trait food cravers) just have a higher likelihood to experience a food craving at the moment of data collection as they generally experience food cravings more frequently. Another possible explanation may be that the general setting in food-related studies (e.g., answering numerous questions on food and eating behavior) may induce stronger food craving in those with higher FCQ-T scores, which would be in line with the food cue reactivity findings described above. Thus, although trait and state food cravings can be differentiated, they are not independent from each other and researchers who assess both should expect that scores of the FCQ-T (or any of its derivatives) and the FCQ-S are correlated. 


\section{Craving Vs. Hunger}

A food craving refers to a strong desire to eat a specific type of food while feelings of hunger refer to the absence of fullness [99]. Moreover, a food craving can also occur without being hungry, that is, food deprivation is not a necessary condition for experiencing food cravings [100]. The FCQ-S includes a subscale for measuring hunger (Items 13-15; Table 2) and the FCQ-T includes a subscale entitled craving as a physiological state (Items 11-14; Table 1), which partially assesses feelings of hunger. Yet, is it possible to differentiate between craving and hunger when using the FCQs?

As stated above, factorial validity of the FCQ-T is limited, that is, differentiating between the nine subscales may not be meaningful. Moreover, the craving as a physiological state subscale had the lowest internal reliability of all subscales in one study [13], and none of the hunger-related items are included in the short versions of the FCQ-T, which were developed through item reduction based on factor analyses [69], item-total correlations [58], or conceptual considerations (i.e., including only items that assess core aspects of food craving [22]). Thus, it may be that the hunger-related items of the FCQ-T are psychometrically unsound. This interpretation would also be in line with findings from other measures that include hunger-related items such as the hunger subscale of the Three-Factor Eating Questionnaire. Here, it has been found that - although the questions do not refer to the present moment - scores on the hunger subscale were influenced by participants' current hunger level [101]. Taken together, these findings suggest that it may be hard for participants to evaluate feelings of hunger in general (and their impact on eating) and to differentiate them from current hunger.

While assessment of hunger feelings with the FCQ-T seems to be problematic, it may be that the differentiation between current food craving and hunger is more straightforward. There is, indeed, some evidence for this. As described above, length of food deprivation correlated with current hunger, but not current craving in a study with the chocolateadapted version of the FCQ-S [93]. Moreover, only current chocolate craving, but not current hunger, related to chocolate cue-induced salivary flow and chocolate consumption. Thus, it seems that current craving and hunger can indeed be differentiated, at least in certain circumstances.

In contrast, both craving and hunger increased during chocolate cue exposure [93]. This is in line with other studies showing that scores on both the craving-related subscales and the hunger subscale of the FCQ-S usually increase during food exposure (e.g., [57]). Thus, it seems that although food craving and hunger can be differentiated in certain circumstances, they are not independent from each other and can also co-occur. An interesting future avenue would be to examine whether this is a methodological artifact as it may be hard for participants to differentiate between food craving and general feelings of hunger when completing the scale. For example, studies may investigate whether providing clear definitions of and highlighting the differences between both constructs in the questionnaire's instructions lead to a clearer differentiation (e.g., with increases only in food craving during food cue exposure and hunger scores remaining stable). Furthermore, it may be worthwhile to examine interactive effects between food craving and hunger when predicting food consumption or other outcome variables, which have rarely been considered in the extant literature [98].

\section{Comparison with Other Food Craving Measures}

There are several self-report measures for the assessment of food cravings other than the FCQs, the most widely used of which is the Food Craving Inventory (FCI; Fig. 1; [102]). The FCI measures the frequency of cravings for specific foods over the past month, which can be separated into four classes: highfat foods, sweet foods, carbohydrate-rich foods/starches, and high-fat fast foods. As the FCQ-T and its derivatives refer to food cravings in general or to one specific food (e.g., chocolate), researchers may want to prefer using the FCI when cravings for different type of food groups need to be assessed. However, because the FCI names specific foods, it necessitates cultural adaptions when applied in different countries. Indeed, there are other versions for which the type of foods were adapted to be more suitable for the British [103], Spanish [104], German [105], Japanese [106], and Brazilian [107] population. These different versions include different foods, numbers of items, and subscales, and may, therefore, not be comparable across studies. Thus, the FCQ-T and its short versions may be more suitable for cross-cultural research [91, 108].

For the assessment of chocolate craving, alternative measures are the Attitudes to Chocolate Questionnaire (ACQ) and the Orientation to Chocolate Questionnaire (OCQ; Fig. 1). The ACQ has been originally developed as a three-dimensional, 24-item questionnaire [109]. Yet, subsequent studies showed that a 22-item, two-factor structure should be preferred, which includes a factor for chocolate craving and a factor for feelings of guilt associated with chocolate consumption [110-112]. The OCQ is a 14-item, three-dimensional questionnaire measuring chocolate craving (approach), avoidance of chocolate, and guilt [113]. The chocolate-adapted FCQ-T (but not the chocolate-adapted FCQ-T-r) includes a subscale on feelings of guilt after eating chocolate as well. Thus, researchers who want to measure chocolate-related guilt in addition to chocolate craving, but want to do this with a shorter questionnaire than the chocolate-adapted FCQ-T, may want to prefer using the ACQ or OCQ. Moreover, the OCQ additionally measures avoidance behavior in relation to chocolate, which are not included in the other questionnaires. 
If researchers need to measure both trait and state food craving, an alternative measure is the Craving Experience Questionnaire (CEQ; Fig. 1). It includes a 10-item form for measuring current craving strength and a 10-item form for measuring craving frequency [114]. Each form has three subscales: intensity, imagery, and intrusiveness. For each form, the type of substance/food can be specified as well as the time point (for the strength form) or the time frame (for the frequency form) that the items refer to. Thus, the scales are well suited for comparative studies that measure craving for different substances (including food). The rationale behind the CEQ was to develop a craving measure that purely assesses the cognitive aspects of craving experiences (i.e., craving intensity, cognitive images and intrusive thoughts about the substance) without confounding other aspects such as consumption behavior and outcome expectancies. Thus, it differs from the rationale behind the FCQs that aimed to develop measures to assess the multidimensional nature of craving experiences (including all the aforementioned aspects). Future research is needed that examines whether the two measures produce divergent findings in food craving studies or whether findings with both scales may actually have more commonalities than differences although they were derived from different approaches.

Besides these food craving measures, there are others such as the Control of Eating Questionnaire [115], the Questionnaire on Craving for Sweet and Rich Foods [116], or the Food Approach and Avoidance Questionnaire [117]. However, these have yet received little attention in the literature. Comprehensive overviews of different food craving questionnaires are also provided elsewhere [118-120].

\section{Conclusions}

The FCQs and their modified versions have excellent internal reliability. Expectedly, the FCQ-T (and its derivatives) has higher retest reliability than the FCQ-S as the FCQ-S is sensitive to situational changes such as food deprivation and food intake. However, while the FCQ-T is largely unaffected by such momentary states, it is also sensitive to change during weight-loss treatments and other interventions. Numerous experimental and longitudinal studies support validity of the FCQs. Yet, evidence for factorial validity is inconsistent, and, thus, the use of total scores or of short versions may be preferable.

Funding Information Open Access funding provided by Projekt DEAL.

Open Access This article is licensed under a Creative Commons Attribution 4.0 International License, which permits use, sharing, adaptation, distribution and reproduction in any medium or format, as long as you give appropriate credit to the original author(s) and the source, provide a link to the Creative Commons licence, and indicate if changes were made. The images or other third party material in this article are included in the article's Creative Commons licence, unless indicated otherwise in a credit line to the material. If material is not included in the article's
Creative Commons licence and your intended use is not permitted by statutory regulation or exceeds the permitted use, you will need to obtain permission directly from the copyright holder. To view a copy of this licence, visit http://creativecommons.org/licenses/by/4.0/.

\section{References}

1. Weingarten HP, Elston D. The phenomenology of food cravings. Appetite. 1990;15:231-46. https://doi.org/10.1016/01956663(90)90023-2.

2. Hormes JM. Perimenstrual chocolate craving: from pharmacology and physiology to cognition and culture. In: Hollins-Martin C, van den Akker O, Martin C, Preedy VR, editors. Handbook of diet and nutrition in the menstrual cycle, periconception and fertility. Wageningen: Wageningen Academic Publishers; 2014. p. 13754.

3. Richard A, Meule A, Reichenberger J, Blechert J. Food cravings in everyday life: an EMA study on snack-related thoughts, cravings, and consumption. Appetite. 2017;113:215-23. https://doi. org/10.1016/j.appet.2017.02.037.

4. Weingarten HP, Elston D. Food cravings in a college population. Appetite. 1991;17:167-75. https://doi.org/10.1016/01956663(91)90019-O.

5. Hill AJ, Heaton-Brown L. The experience of food craving: a prospective investigation in healthy women. J Psychosom Res. 1994;38:801-14. https://doi.org/10.1016/0022-3999(94)90068$\mathrm{X}$.

6. Osman JL, Sobal J. Chocolate cravings in American and Spanish individuals: biological and cultural influences. Appetite. 2006;47: 290-301. https://doi.org/10.1016/j.appet.2006.04.008.

7. Rodin J, Mancuso J, Granger J, Nelbach E. Food cravings in relation to body mass index, restraint and estradiol levels: a repeated measures study in healthy women. Appetite. 1991;17:177-85. https://doi.org/10.1016/0195-6663(91)90020-S.

8. Rozin P, Levine E, Stoess C. Chocolate craving and liking. Appetite. 1991;17:199-212. https://doi.org/10.1016/01956663(91)90022-K.

9. Rodríguez-Martín BC, Meule A. Food craving: new contributions on its assessment, moderators, and consequences. Front Psychol. 2015;6(21):1-3. https://doi.org/10.3389/fpsyg.2015.00021.

10. Hallam J, Boswell RG, DeVito EE, Kober H. Gender-related differences in food craving and obesity. Yale J Biol Med. 2016;89: 161-73.

11. Cepeda-Benito A, Gleaves DH, Williams TL, Erath SA. The development and validation of the state and trait food-cravings questionnaires. Behav Ther. 2000;31:151-73. https://doi.org/10.1016/ S0005-7894(00)80009-X.

12. Cepeda-Benito A, Gleaves DH, Fernández MC, Vila J, Williams TL, Reynoso J. The development and validation of Spanish versions of the State and Trait Food Cravings Questionnaires. Behav Res Ther. 2000;38:1125-38. https://doi.org/10.1016/S00057967(99)00141-2.

13. Meule A, Lutz A, Vögele C, Kübler A. Food cravings discriminate differentially between successful and unsuccessful dieters and non-dieters. Validation of the Food Cravings Questionnaires in German. Appetite. 2012;58:88-97. https://doi.org/10.1016/j. appet.2011.09.010.

14. Innamorati $\mathrm{M}$, Imperatori $\mathrm{C}$, Balsamo $\mathrm{M}$, Tamburello $\mathrm{S}$, Belvederi Murri M, Contardi A, et al. Food Cravings Questionnaire-Trait (FCQ-T) discriminates between obese and overweight patients with and without binge eating tendencies: the Italian version of 
the FCQ-T. J Pers Assess. 2014;96:632-9. https://doi.org/10. 1080/00223891.2014.909449.

15. Ulian MD, Sato PM, Benatti FB, Campos-Ferraz PLD, Roble OJ, Unsain RF, et al. Cross-cultural adaptation of the State and Trait Food Cravings Questionnaires (FCQ-S and FCQ-T) into Portuguese. Ciência \& Saúde Coletiva. 2017;22:403-16. https:// doi.org/10.1590/1413-81232017222.18272015.

16. Queiroz de Medeiros AC, Campos Pedrosa LF, Hutz CS, Yamamoto ME. Brazilian version of food cravings questionnaires: Psychometric properties and sex differences. Appetite. 2016;105:328-33. https://doi.org/10.1016/j.appet.2016.06.003.

17. Kachooei M, Ashrafi E. Exploring the factor structure, reliability and validity of the Food Craving Questionnaire-Trait in Iranian adults. J Kerman Univ Med Sci. 2016;23:631-48.

18. Muftuoglu S, Kiziltan G, Akçil OM. The reliability and validity of the Turkish version of Food Cravings Questionnaire (FCQ-T) in major depressive disorder patients. Psychiatry Behav Sci. 2018;8: 18-25. https://doi.org/10.5455/jmood.20180302125342.

19. Yu M, Qian M-Y. Reliability and validity of the food-cravings questionnaire-trait in Chinese female college students. Chin J Clin Psychol. 2016;24:675-9.

20. Cepeda-Benito A, Fernandez MC, Moreno S. Relationship of gender and eating disorder symptoms to reported cravings for food: construct validation of state and trait craving questionnaires in Spanish. Appetite. 2003;40:47-54. https://doi.org/10.1016/ S0195-6663(02)00145-9.

21. Moreno S, Rodríguez S, Fernandez MC, Tamez J, Cepeda-Benito A. Clinical validation of the trait and state versions of the Food Craving Questionnaire. Assessment. 2008;15:375-87. https://doi. org/10.1177/1073191107312651.

22. Maranhão MF, Estella NM, Cogo-Moreira H, Schmidt U, Campbell IC, Claudino AM. Concept and evaluation of food craving: unidimensional scales based on the Trait and the State Food Craving Questionnaire. Cadernos de Saúde Pública. 2018;34(5):e00144717. https://doi.org/10.1590/0102$311 X 00144717$.

23. Vander Wal JS, Johnston KA, Dhurandhar NV. Psychometric properties of the State and Trait Food Cravings Questionnaires among overweight and obese persons. Eat Behav. 2007;8:21123. https://doi.org/10.1016/j.eatbeh.2006.06.002.

24. Crowley NM, LePage ML, Goldman RL, O'Neil PM, Borckardt JJ, Byrne TK. The food craving questionnaire-trait in a bariatric surgery seeking population and ability to predict post-surgery weight loss at six months. Eat Behav. 2012;13:366-70. https:// doi.org/10.1016/j.eatbeh.2012.07.003.

25. Crowley N, Madan A, Wedin S, Correll JA, Delustro LM, Borckardt JJ, et al. Food cravings among bariatric surgery candidates. Eat Weight Disord. 2014;19:371-6. https://doi.org/10. 1007/s40519-013-0095-y.

26. Rodríguez-Martín B, Molerio-Pérez O. Exploring the factor structure of the Food Cravings Questionnaire-Trait in Cuban adults. Front Psychol. 2014;5(214):1-12. https://doi.org/10.3389/fpsyg. 2014.00214.

27. Batra P, Das SK, Salinardi T, Robinson L, Saltzman E, Scott T, et al. Relationship of cravings with weight loss and hunger. Results from a 6 month worksite weight loss intervention. Appetite. 2013;69:1-7. https://doi.org/10.1016/j.appet.2013.05. 002.

28. Abilés V, Rodríguez-Ruiz S, Abilés J, Obispo A, Gandara N, Luna $\mathrm{V}$, et al. Effectiveness of cognitive-behavioral therapy in morbidity obese candidates for bariatric surgery with and without binge eating disorder. Nutr Hosp. 2013;28:1523-9. https://doi.org/10.3305/ nh.2013.28.5.6699.

29. Rodríguez-Martín BC, Gómez-Quintana A, Díaz-Martínez G, Molerio-Pérez O. Bibliotherapy and food cravings control.
Appetite. 2013;65:90-5. https://doi.org/10.1016/j.appet.2013.02. 006.

30. Meule A, Freund R, Skirde AK, Vögele C, Kübler A. Heart rate variability biofeedback reduces food cravings in high food cravers. Appl Psychophysiol Biofeedback. 2012;37:241-51. https://doi.org/10.1007/s10484-012-9197-y.

31. Schmidt J, Martin A. Neurofeedback reduces overeating episodes in female restrained eaters: a randomized controlled pilot-study. Appl Psychophysiol Biofeedback. 2015;40(4):283-95. https://doi. org/10.1007/s10484-015-9297-6.

32. Brockmeyer T, Hahn C, Reetz C, Schmidt U, Friederich H-C. Approach bias modification in food craving - a proof-of-concept study. Eur Eat Disord Rev. 2015;23:352-60. https://doi.org/10. 1002/erv.2382.

33. Giel KE, Rieber N, Enck P, Friederich H-C, Meile T, Zipfel S, et al. Effects of laparoscopic sleeve gastrectomy on attentional processing of food-related information: evidence from eye-tracking. Surg Obes Relat Dis. 2014;10:277-82. https://doi.org/10. 1016/j.soard.2013.09.012.

34. Imperatori $\mathrm{C}$, Innamorati $\mathrm{M}$, Tamburello $\mathrm{S}$, Continisio $\mathrm{M}$, Contardi A, Tamburello A, et al. Gender differences in food craving among overweight and obese patients attending low energy diet therapy: a matched case-control study. Eat Weight Disord. 2013;18:297-303. https://doi.org/10.1007/s40519-013-0054-7.

35. van den Eynde F, Giampietro V, Simmons A, Uher R, Andrew $\mathrm{CM}$, Harvey P-O, et al. Brain responses to body image stimuli but not food are altered in women with bulimia nervosa. BMC Psychiatry. 2013;13(302):1-13. https://doi.org/10.1186/1471244x-13-302.

36. Leslie M, Turton R, Burgess E, Nazar BP, Treasure J. Testing the addictive appetite model of binge eating: the importance of craving, coping, and reward enhancement. Eur Eat Disord Rev. 2018;26:541-50. https://doi.org/10.1002/erv.2621.

37. van den Eynde F, Koskina A, Syrad H, Guillaume S, Broadbent H, Campbell IC, et al. State and trait food craving in people with bulimic eating disorders. Eat Behav. 2012;13:414-7. https://doi. org/10.1016/j.eatbeh.2012.07.007.

38. Abilés V, Rodríguez-Ruiz S, Abilés J, Mellado C, García A, de la Cruz Pérez A, et al. Psychological characteristics of morbidly obese candidates for bariatric surgery. Obes Surg. 2010;20:1617. https://doi.org/10.1007/s11695-008-9726-1.

39. Franken IHA, Muris P. Individual differences in reward sensitivity are related to food craving and relative body weight in healthy women. Appetite. 2005;45:198-201. https://doi.org/10.1016/j. appet.2005.04.004.

40. Meule A. Impulsivity and overeating: a closer look at the subscales of the Barratt impulsiveness scale. Front Psychol. 2013;4(177):1-4. https://doi.org/10.3389/fpsyg.2013.00177.

41. Fabbricatore M, Imperatori C, Morgia A, Contardi A, Tamburello $\mathrm{S}$, Innamorati $\mathrm{M}$, et al. Food craving and personality dimensions in overweight and obese patients attending low energy diet therapy. Obes Metab. 2011;7:28-34.

42. Vainik U, Neseliler S, Konstabel K, Fellows LK, Dagher A. Eating traits questionnaires as a continuum of a single concept. Uncontrolled Eating Appetite. 2015;90:229-39. https://doi.org/ 10.1016/j.appet.2015.03.004.

43. Vainik U, García-García I, Dagher A. Uncontrolled eating: a unifying heritable trait linked with obesity, overeating, personality and the brain. Eur J Neurosci. 2019;50:2430-2445. https://oi. org/10.1111/ejn.14352.

44. Brockmeyer T, Hahn C, Reetz C, Schmidt U, Friederich H-C. Approach bias and cue reactivity towards food in people with high versus low levels of food craving. Appetite. 2015;95:197-202. https://doi.org/10.1016/j.appet.2015.07.013.

45. Meule A, Skirde AK, Freund R, Vögele C, Kübler A. High-calorie food-cues impair working memory performance in high and low 
food cravers. Appetite. 2012;59:264-9. https://doi.org/10.1016/j. appet.2012.05.010.

46. Tiggemann M, Kemps E. The phenomenology of food cravings: the role of mental imagery. Appetite. 2005;45:305-13. https://doi. org/10.1016/j.appet.2005.06.004.

47. Ulrich M, Steigleder L, Grön G. Neural signature of the Food Craving Questionnaire (FCQ)-trait. Appetite. 2016;107:303-10. https://doi.org/10.1016/j.appet.2016.08.012.

48. Meule A, Kübler A. Double trouble. Trait food craving and impulsivity interactively predict food-cue affected behavioral inhibition. Appetite. 2014;79:174-82. https://doi.org/10.1016/j.appet. 2014.04.014.

49. Davis C, Loxton NJ, Levitan RD, Kaplan AS, Carter JC, Kennedy JL. 'Food addiction' and its association with a dopaminergic multilocus genetic profile. Physiol Behav. 2013;118:63-9. https://doi.org/10.1016/j.physbeh.2013.05.014.

50. Hofmann J, Meule A, Reichenberger J, Weghuber D, ArdeltGattinger E, Blechert J. Crave, like, eat: determinants of food intake in a sample of children and adolescents with a wide range in body mass. Front Psychol. 2016;7(1389):1-9. https://doi.org/ 10.3389/fpsyg.2016.01389.

51. Janse Van Vuuren MA, Strodl E, White KM, Lockie PD. Emotional food cravings predicts poor short-term weight loss following laparoscopic sleeve gastrectomy. Br J Health Psychol. 2018;23:532-43. https://doi.org/10.1111/bjhp.12302.

52. Lombardo C, Iani L, Barbaranelli C. Validation of an Italian version of the Food Craving Questionnaire-State: factor structure and sensitivity to manipulation. Eat Behav. 2016;22:182-7. https://doi. org/10.1016/j.eatbeh.2016.06.003.

53. Yu JH, Shin MS, Kim DJ, Lee JR, Yoon S-Y, Kim SG, et al. Enhanced carbohydrate craving in patients with poorly controlled type 2 diabetes mellitus. Diabet Med. 2013;30:1080-6. https://doi. org/10.1111/dme.12209.

54. Ng L, Davis C. Cravings and food consumption in binge eating disorder. Eat Behav. 2013;14:472-5. https://doi.org/10.1016/j. eatbeh.2013.08.011.

55. Meule A, Teran CB, Berker J, Gründel T, Mayerhofer M, Platte P. On the differentiation between trait and state food craving: halfyear retest-reliability of the Food Cravings Questionnaire-Traitreduced (FCQ-T-r) and the Food Cravings Questionnaire-State (FCQ-S). J Eat Disord. 2014;2(25):1-3. https://doi.org/10.1186/ s40337-014-0025-z.

56. Meule A, Küppers C, Harms L, Friederich H-C, Schmidt U, Blechert J, et al. Food cue-induced craving in individuals with bulimia nervosa and binge-eating disorder. PLoS One. 2018;13(9):e0204151. https://doi.org/10.1371/journal.pone. 0204151.

57. Meule A, Kübler A. A pilot study on the effects of slow paced breathing on current food craving. Appl Psychophysiol Biofeedback. 2017;42:59-68. https://doi.org/10.1007/s10484017-9351-7.

58. Meule A, Hermann T, Kübler A. A short version of the Food Cravings Questionnaire-Trait: the FCQ-T-reduced. Front Psychol. 2014;5(190):1-10. https://doi.org/10.3389/fpsyg.2014. 00190.

59. Georgii C, Goldhofer P, Meule A, Richard A, Blechert J. Food craving, food choice and consumption: the role of impulsivity and sham-controlled tDCS stimulation of the right dIPFC. Physiol Behav. 2017;177:20-6. https://doi.org/10.1016/j.physbeh.2017. 04.004 .

60. McVay MA, Copeland AL, Newman HS, Geiselman PJ. Food cravings and food cue responding across the menstrual cycle in a non-eating disordered sample. Appetite. 2012;59:591-600. https://doi.org/10.1016/j.appet.2012.07.011.

61. Karyadi KA, Cyders MA. Preliminary support for the role of alcohol cues in food cravings and attentional biases. J Health
Psychol. 2019;24:812-22. https://doi.org/10.1177/ 1359105316685898 .

62. Taylor AH, Oliver AJ. Acute effects of brisk walking on urges to eat chocolate, affect, and responses to a stressor and chocolate cue. An experimental study. Appetite. 2009;52:155-60. https://doi.org/ 10.1016/j.appet.2008.09.004.

63. Davis C, Fattore L, Kaplan AS, Carter JC, Levitan RD, Kennedy JL. The suppression of appetite and food consumption by methylphenidate: the moderating effects of gender and weight status in healthy adults. Int J Neuropsychopharmacol. 2012;15:181-7. https://doi.org/10.1017/s1461145711001039.

64. van den Eynde F, Broadbent H, Guillaume S, Claudino A, Campbell IC, Schmidt U. Handedness, repetitive transcranial magnetic stimulation and bulimic disorders. European Psychiatry. 2012;27:290-3. https://doi.org/10.1016/j.eurpsy. 2010.08.015.

65. van den Eynde F, Claudino AM, Mogg A, Horrell L, Stahl D, Ribeiro W, et al. Repetitive transcranial magnetic stimulation reduces cue-induced food craving in bulimic disorders. Biol Psychiatry. 2010;67:793-5. https://doi.org/10.1016/j.biopsych. 2009.11.023.

66. Leong SL, Vanneste S, Lim J, Smith M, Manning P, De Ridder D. A randomised, double-blind, placebo-controlled parallel trial of closed-loop infraslow brain training in food addiction. Sci Rep. 2018;8(11659):1-9. https://doi.org/10.1038/s41598-018-301817.

67. Hofmann W, van Koningsbruggen GM, Stroebe W, Ramanathan $\mathrm{S}$, Aarts H. As pleasure unfolds: hedonic responses to tempting food. Psychol Sci. 2010;21:1863-70. https://doi.org/10.1177/ 0956797610389186.

68. Meule A, Lutz APC, Vögele C, Kübler A. Impulsive reactions to food-cues predict subsequent food craving. Eat Behav. 2014;15: 99-105. https://doi.org/10.1016/j.eatbeh.2013.10.023.

69. Nijs IMT, Franken IHA, Muris P. The modified Trait and State Food-Cravings Questionnaires: development and validation of a general index of food craving. Appetite. 2007;49:38-46. https:// doi.org/10.1016/j.appet.2006.11.001.

70. Alberts HJEM, Thewissen R, Middelweerd M. Accepting or suppressing the desire to eat: investigating the short-term effects of acceptance-based craving regulation. Eat Behav. 2013;14:405-9. https://doi.org/10.1016/j. eatbeh.2013.06.008.

71. Yang C-L, Schnepp J, Tucker RM. Increased hunger, food cravings, food reward, and portion size selection after sleep curtailment in women without obesity. Nutrients. 2019;11(663):1-12. https://doi.org/10.3390/nu11030663.

72. Watson NA, Dyer KA, Buckley JD, Brinkworth GD, Coates AM, Parfitt G, et al. Reductions in food cravings are similar with lowfat weight loss diets differing in protein and carbohydrate in overweight and obese adults with type 2 diabetes: a randomized clinical trial. Nutr Res. 2018;57:56-66. https://doi.org/10.1016/j. nutres.2018.05.005.

73. Alfonsson S, Sundbom M, Ghaderi A. Is age a better predictor of weight loss one year after gastric bypass than symptoms of disordered eating, depression, adult ADHD and alcohol consumption? Eat Behav. 2014;15:644-7. https://doi.org/10.1016/j. eatbeh.2014. 08.024 .

74. Alberts HJEM, Mulkens S, Smeets M, Thewissen R. Coping with food cravings. Investigating the potential of a mindfulness-based intervention. Appetite. 2010;55:160-3. https://doi.org/10.1016/j. appet.2010.05.044.

75. Alberts HJEM, Thewissen R, Raes L. Dealing with problematic eating behaviour. The effects of a mindfulness-based intervention on eating behaviour, food cravings, dichotomous thinking and body image concern. Appetite. 2012;58:847-51. https://doi.org/ 10.1016/j.appet.2012.01.009. 
76. Noh JH, Kim JH, Nam HJ, Lim MR, Lee DS, Hong KS. Validation of the Korean version of the General Food Cravings Questionnaire-Trait (G-FCQ-T). Korean J Clin Psychol. 2008;27: 1039-51.

77. Jeong J-E, Jung D-J, Kwak M, Kyung Yang H, Lim S-Y, Lee J-H, et al. Reliability and validity of the Korean version of the GeneralFood Craving Questionnaire-Trait for children. Psychiatry Investig. 2017;14:595-602. https://doi.org/10.4306/pi.2017.14.5. 595 .

78. Hormes JM, Meule A. Psychometric properties of the English Food Cravings Questionnaire-Trait-reduced (FCQ-T-r). Eat Behav. 2016;20:34-8. https://doi.org/10.1016/j.eatbeh.2015.11. 011.

79. Queiroz de Medeiros AC, Pedrosa LDFC, Yamamoto ME. Exploring the structural and construct validity of the Brazilian Food Cravings Questionnaire-Trait-reduced (FCQ-T-r). Br J Psychiatry. 2019;41:66-9. https://doi.org/10.1590/1516-44462017-0019.

80. Brunault P, El Archi S, Ballon N, Réveillère C, Barrault S. Validation of the French version of the food cravings Questionaire-trait-reduced: an easy-to-use and quick selfadministered questionnaire to assess food craving. Ann Med Psychol. 2018;176:788-95. https://doi.org/10.1016/j.amp.2018. 08.002 .

81. Mohammadi MR, Akhondzadeh S, Mostafavi S-A, Keshavarz SA, Motlaq TA, Eshraghian MR, et al. The reliability and validity of the Persian version of Food Craving Questionnaire-TraitReduced (FCQ-T-r) in overweight and obese women. J Nutr Fasting Health. 2018;6:150-7. https://doi.org/10.22038/JNFH. 2018.35221.1150.

82. Innamorati M, Imperatori C, Meule A, Lamis DA, Contardi A, Balsamo M, et al. Psychometric properties of the Italian Food Cravings Questionnaire-Trait-reduced (FCQ-T-r). Eat Weight Disord. 2015;20:129-35. https://doi.org/10.1007/s40519-0140143-2.

83. Iani L, Barbaranelli C, Lombardo C. Cross-validation of the reduced form of the Food Craving Questionnaire-Trait using confirmatory factor analysis. Front Psychol. 2015;6(433):1-8. https:// doi.org/10.3389/fpsyg.2015.00433.

84. Meule A. Food cravings in food addiction: exploring a potential cut-off value of the Food Cravings Questionnaire-Trait-reduced. Eat Weight Disord. 2018;23:39-43. https://doi.org/10.1007/ s40519-017-0452-3.

85. Sutin AR, Boutelle K, Czajkowski SM, Epel ES, Green PA, Hunter CM, et al. Accumulating data to Optimally Predict Obesity Treatment (ADOPT) core measures: psychosocial domain. Obesity. 2018;26:S45-54. https://doi.org/10.1002/oby. 22160 .

86. Schmidt J, Martin A. Neurofeedback against binge eating: a randomized controlled trial in a female subclinical threshold sample. Eur Eat Disord Rev. 2016;24:406-16. https://doi.org/10.1002/erv. 2453.

87. Mason AE, Jhaveri K, Cohn M, Brewer JA. Testing a mobile mindful eating intervention targeting craving-related eating: feasibility and proof of concept. J Behav Med. 2018;41:160-73. https://doi.org/10.1007/s10865-017-9884-5.

88. Schnepper R, Richard A, Wilhelm FH, Blechert J. A combined mindfulness-prolonged chewing intervention reduces body weight, food craving, and emotional eating. J Consult Clin Psychol. 2019;87:106-11. https://doi.org/10.1037/ccp0000361.

89. Meule A, Richard A, Platte P. Food cravings prospectively predict decreases in perceived self-regulatory success in dieting. Eat Behav. 2017;24:34-8. https://doi.org/10.1016/j.eatbeh.2016.11. 007.

90. Reichenberger J, Smyth JM, Kuppens P, Blechert J. "I will fast ... tomorrow": intentions to restrict eating and actual restriction in daily life and their person-level predictors. Appetite. 2019;140: 10-8. https://doi.org/10.1016/j.appet.2019.04.019.

91. Rodríguez S, Warren CS, Moreno S, Cepeda-Benito A, Gleaves DH, del Carmen Fernández M, et al. Adaptation of the foodcraving questionnaire trait for the assessment of chocolate cravings: validation across British and Spanish women. Appetite. 2007;49:245-50. https://doi.org/10.1016/j.appet.2007.01.001.

92. Moreno-Dominguez S, Rodríguez-Ruiz S, Martín M, Warren CS. Experimental effects of chocolate deprivation on cravings, mood, and consumption in high and low chocolate-cravers. Appetite. 2012;58:111-6. https://doi.org/10.1016/j.appet.2011.09.013.

93. Meule A, Hormes JM. Chocolate versions of the Food Cravings Questionnaires. Associations with chocolate exposure-induced salivary flow and ad libitum chocolate consumption. Appetite. 2015;91:256-65. https://doi.org/10.1016/j.appet.2015.04.054.

94. Meule A, Richard A, Dinic R, Blechert J. Effects of a smartphonebased approach-avoidance intervention on chocolate craving and consumption: randomized controlled trial. JMIR mHealth and uHealth . 2019;7:e12298. https://doi.org/10.2196/12298.

95. Miedl SF, Blechert J, Meule A, Richard A, Wilhelm FH. Suppressing images of desire: neural correlates of chocolaterelated thoughts in high and low trait chocolate cravers. Appetite. 2018;126:128-36. https://doi.org/10.1016/j.appet. 2018.03.004.

96. Meule A, Lender A, Richard A, Dinic R, Blechert J. Approachavoidance tendencies towards food: measurement on a touchscreen and the role of attention and food craving. Appetite. 2019;137:145-51. https://doi.org/10.1016/j.appet.2019.03.002.

97. Richard A, Meule A, Friese M, Blechert J. Effects of chocolate deprivation on implicit and explicit evaluation of chocolate in high and low trait chocolate cravers. Front Psychol. 2017;8(1591):111. https://doi.org/10.3389/fpsyg.2017.01591.

98. Richard A, Meule A, Blechert J. When and how do explicit measures of food craving predict implicit food evaluation? A moderated mediation model. Food Qual Prefer. 2018;66:141-7. https:// doi.org/10.1016/j.foodqual.2018.01.018.

99. Rogers PJ, Brunstrom JM. Appetite and energy balancing. Physiol Behav. 2016;164:465-71. https://doi.org/10.1016/j.physbeh. 2016.03.038.

100. Pelchat ML, Schaefer S. Dietary monotony and food cravings in young and elderly adults. Physiol Behav. 2000;68:353-9. https:// doi.org/10.1016/S0031-9384(99)00190-0.

101. Yeomans MR, McCrickerd K. Acute hunger modifies responses on the Three Factor Eating Questionnaire hunger and disinhibition, but not restraint, scales. Appetite. 2017;110:1-5. https://doi. org/10.1016/j.appet.2016.12.008.

102. White MA, Whisenhunt BL, Williamson DA, Greenway FL, Netemeyer RG. Development and validation of the FoodCraving Inventory. Obes Res. 2002;10:107-14. https://doi.org/ 10.1038/oby.2002.17.

103. Nicholls W, Hulbert-Williams L. British English translation of the Food Craving Inventory (FCI-UK). Appetite. 2013;67:37-43. https://doi.org/10.1016/j.appet.2013.03.010.

104. Jáuregui-Lobera I, Bolaños P, Carbonero R, Valero BE. Psychometric properties of the Spanish version of Food Craving Inventory (FCI-SP). Nutr Hosp. 2010;25:984-92. https://doi.org/ 10.3305/nh.2010.25.6.4967.

105. Tarragon E, Stein J, Meyer J. Psychometric properties of the German translated version and adaptation of the Food Craving Inventory. Front Psychol. 2017;8(736):1-7. https://doi.org/10. 3389/fpsyg.2017.00736.

106. Komatsu S. Rice and sushi cravings: a preliminary study of food craving among Japanese females. Appetite. 2008;50:353-8. https://doi.org/10.1016/j.appet.2007.08.012. 
107. Queiroz de Medeiros AC, Pedrosa LDFC, Yamamoto ME. Food cravings among Brazilian population. Appetite. 2017;108:212-8. https://doi.org/10.1016/j.appet.2016.10.009.

108. Rodríguez-Martín BC, Innamorati M, Imperatori C, Fabbricatore M, Harnic D, Janiri L, et al. Eating behaviors in Cuban adults: results from an exploratory transcultural study. Front Psychol. 2016;7(1455):1-7. https://doi.org/10.3389/fpsyg.2016.01455.

109. Benton D, Greenfield K, Morgan M. The development of the attitudes to chocolate questionnaire. Personal Individ Differ. 1998;24:513-20. https://doi.org/10.1016/S0191-8869(97)002158.

110. Cramer KM, Hartleib M. The attitudes to chocolate questionnaire: a psychometric evaluation. Personal Individ Differ. 2001;31:93142. https://doi.org/10.1016/S0191-8869(00)00195-1.

111. Müller J, Dettmer D, Macht M. The attitudes to chocolate questionnaire: psychometric properties and relationship to dimensions of eating. Appetite. 2008;50:499-505. https://doi.org/10.1016/j. appet.2007.10.008.

112. Van Gucht D, Soetens B, Raes F, Griffith JW. The attitudes to chocolate questionnaire. Psychometric properties and relationship with consumption, dieting, disinhibition and thought suppression. Appetite. 2014;76:137-43. https://doi.org/10.1016/j.appet.2014. 01.078 .

113. Cartwright F, Stritzke WGK. A multidimensional ambivalence model of chocolate craving: construct validity and associations with chocolate consumption and disordered eating. Eat Behav. 2008;9:1-12. https://doi.org/10.1016/j.eatbeh.2007.01.006.

114. May J, Andrade J, Kavanagh DJ, Feeney GFX, Gullo MJ, Statham DJ, et al. The craving experience questionnaire: a brief, theory- based measure of consummatory desire and craving. Addiction. 2014;109:728-35. https://doi.org/10.1111/add.12472.

115. Dalton M, Finlayson G, Hill A, Blundell J. Preliminary validation and principal components analysis of the control of eating questionnaire (CoEQ) for the experience of food craving. Eur J Clin Nutr. 2015;69:1313-7. https://doi.org/10.1038/ejcn.2015.57.

116. Toll BA, Katulak NA, Williams-Piehota P, O’Malley S. Validation of a scale for the assessment of food cravings among smokers. Appetite. 2008;50:25-32. https://doi.org/10.1016/j.appet.2007. 05.001.

117. Rancourt, D., Ahlich, E., Levine, J.A., Lee, M.S., \& Schlauch, R.C. (2019). Applying a multidimensional model of craving to disordered eating behaviors: development of the Food Approach and Avoidance Questionnaire. Psychological Assessment, 31, 751-764. https://doi.org/10.1037/pas0000697

118. Meule A. Assessment of food cravings. In: Ifland J, Marcus MT, Preuss HG, editors. Processed food addiction: foundations, assessment, and recovery. Boca Raton: CRC Press; 2018. p. 137-45.

119. Taylor M. A review of food craving measures. Eat Behav. 2019;32:101-10. https://doi.org/10.1016/j.eatbeh.2019.01.005.

120. Martin CK, McClernon FJ, Chellino A, Correa JB. Food cravings: a central construct in food intake behavior, weight loss, and the neurobiology of appetitive behavior. In: Preedy VR, Watson R, Martin C, editors. Handbook of behavior, food and nutrition. New York: Springer; 2011.

Publisher's Note Springer Nature remains neutral with regard to jurisdictional claims in published maps and institutional affiliations. 